\title{
FRICTION TECHNIQUE FOR DETERMINING FORMING LIMIT CURVES
}

\author{
A.Alsaati ${ }^{\text {a }}$, W.J.Ali ${ }^{\text {b }}$, F.M.Alkaissy ${ }^{\text {c }}$ \\ a Dept. of Architectural Eng., College of Eng., Univ. of Mosul, Iraq \\ b Dept. of Mech. Eng., College of Eng. , Univ. of Mosul, Iraq \\ c Dept. of Mech. Eng., Technical Inst. , Mosul, Iraq
}

\begin{abstract}
A new method for establishing the Forming Limit curve (FLC) in sheet metal forming is introduced in this work. The method is based on varying the strain path by changing the coefficient of friction between the punch and the blank.

Three finite element simulations are used for the hemispherical punch stretching test. One simulation is for the positive minor strain side and two are for the negative minor strain side of the FLC. Relations between the major and the minor strains are deduced from the results of these simulations. These relations are used to draw the FLC.

The curves obtained were compared with experimental results and found to have a good agreement with them.
\end{abstract}

KEYWORDS strain path, forming limit curve

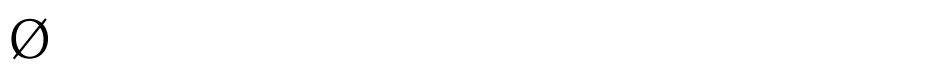

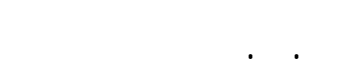

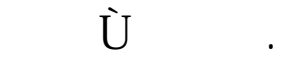

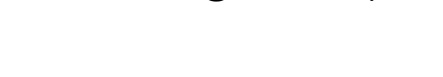

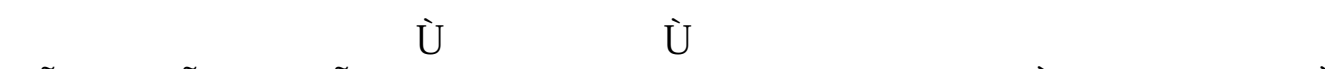

ŭ B̈̌̃̄D

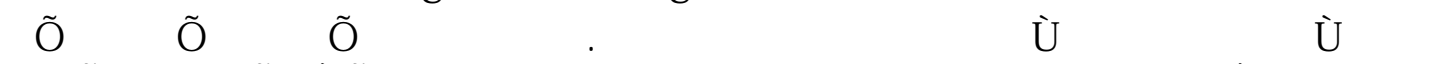

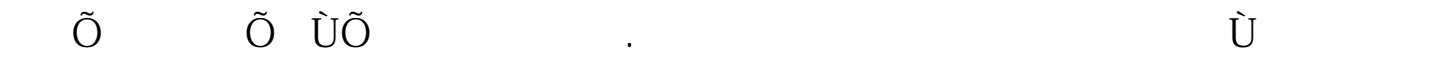

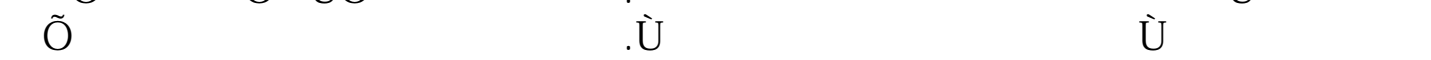

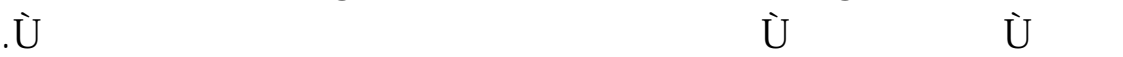

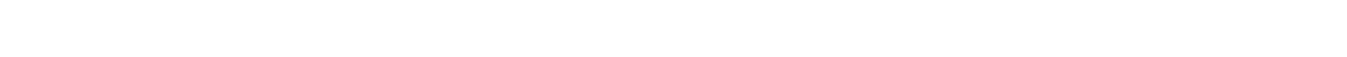

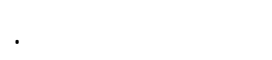




\begin{tabular}{llll} 
Al-Rafidain Engineering & Vol.14 & No.4 & 2006 \\
\hline
\end{tabular}

\section{INTRODUCTION}

The metal forming simulation finite element package LS_DYNA [1] is used. A different selected specimen size [2] is used for the hemispherical punch stretching test [3]. In this test a hemispherical punch of $25 \mathrm{~mm}$ in radius, blanks of different sizes and a die corner radius of $5 \mathrm{~mm}$ are used.

It is well known that the FLC can be constructed either by experimental methods or by theoretical methods. The method of construction of the FLC experimentally was developed by Keeler [4], and by Goodwin [5].It relies on the fact that changing the blank shape will change the strain path. This method is still in use with some modifications. It is well known that it is costly both in time and effort.

Theoretical methods were introduced to compensate for the experimental methods. The conventional theoretical methods used to predict localized necking are basically of two types:

1_ M_K method. The assumption of an initial weakness, imperfection or inhomogeniety in the sheet; as straining proceeds, the imperfection gradually develops into a neck [6].

2_ Linear method. It describes the initiation of localized band of straining in an otherwise uniform sheet, in order to obtain an explicit expression for predicting the limit strains [7], [8].

Both theoretical methods of prediction of FLC are found to be ineffecient. In addition, the M_K method suffers from the arbitrary selection of an imperfect size which often results in inconsistent predictions [9]. A series of modifications have been introduced on these methods in order to produce FLCs that are consistent with experimental curves.

A new method for constructing the FLC is developed in this work. It relies on the fact that the strain path changes by changing the coefficient of friction $\mu$ between the punch and the sheet metal [10]. The strain path is varied by changing the coefficient of friction, the major strain $\boldsymbol{\varepsilon}_{1}$ and minor strain $\boldsymbol{\varepsilon}_{2}$ at the points of localized necking for each strain path are recorded. Also the values of the strain hardening exponent $\mathbf{n}$ and the major strain at plain strain state $\boldsymbol{\varepsilon}_{\mathbf{1 0}}$ are recorded when varying $\mathbf{n}$ and keeping the initial thickness $\mathbf{t}_{\mathbf{0}}$ constant, then the values of $\mathbf{t}_{\mathbf{0}}$ and $\boldsymbol{\varepsilon}_{\mathbf{1 0}}$ are recorded when varying $\mathbf{t}_{\mathbf{0}}$ and keeping $\mathbf{n}$ constant.

The steps of the procedure for drawing the FLC are:

1_ Determination of the level of the FLC at plain strain state $\left(\boldsymbol{\varepsilon}_{2}=0\right)$.

2_ Finding the relation between $\boldsymbol{\varepsilon}_{1}$ and $\boldsymbol{\varepsilon}_{2}$ at localized necking for different strain paths.

3 This relation is used to draw the FLC.

The above procedure is followed to draw the FLCs for the three metals; mild steel, aluminum and brass.

All the curves obtained by this new method were compared to the curves obtained experimentally and found to be in good agreement. 


\section{FINITE ELEMENT SIMULATION}

Fig (1) shows schematics of tool set up geometry, punch, blank holder, die and tested specimen.

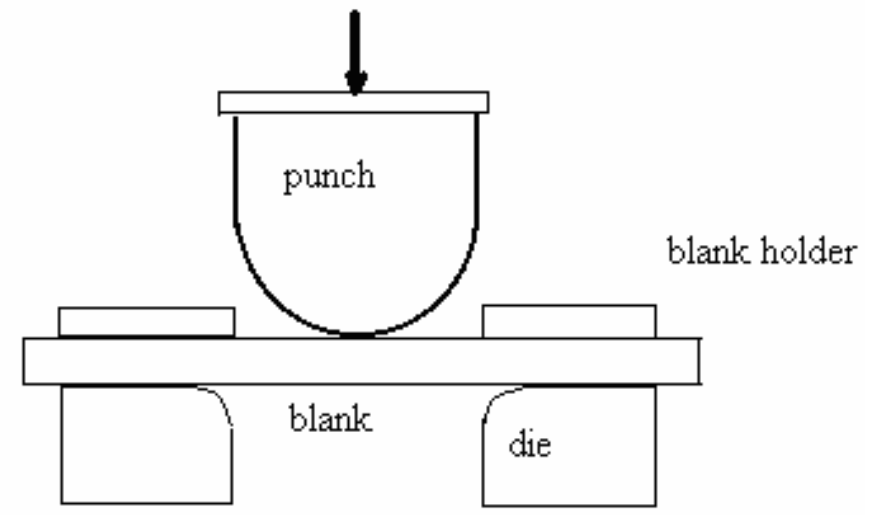

Fig (1). Schematics of tool set up geometry

Fig (2) shows the finite element model for one of the simulations which has been created using ANSYS (5.3) package [11].

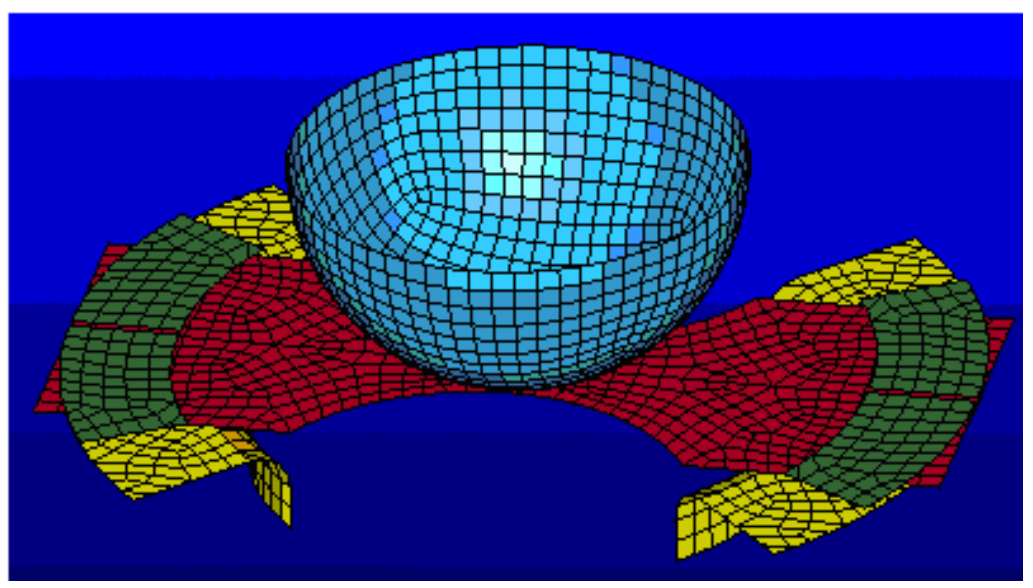

Fig (2). Finite element model for the test (specimen c fig.3)

The three specimens which have been used in the simulations are shown in fig. (3). 


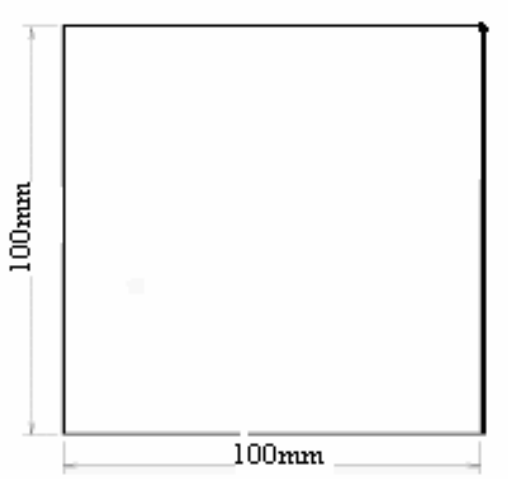

a

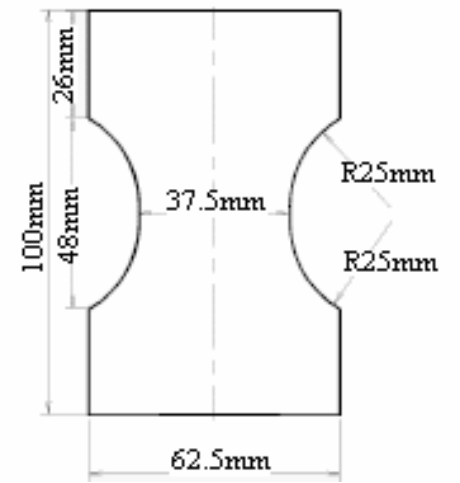

b

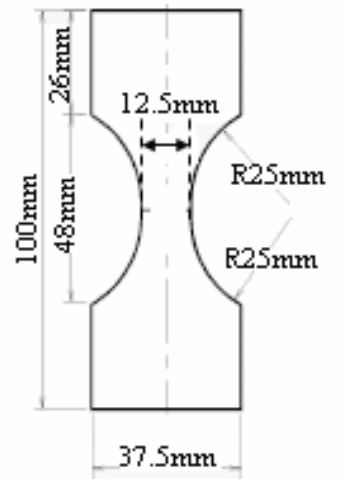

C

fig.(3). The three specimens used in the test [2]

Due to the two fold symmetry of the process, FE descritization is considered for one quarter of the specimens. For simulation no.1 a uniform mesh of 400 shell elements with one point quadrature are used for the blank (specimen a, fig 3), 192 for the punch, 320 for the blank holder and 640 for the die. For simulation no. 2 a uniform mesh of 272 shell elements with 5 integration points are used for the blank(specimen b, fig 3),192 for the punch, 92 for the blank holder and 254 for the die. For simulation no.3 a uniform mesh of 152 shell elements with 5 integration points are used for the blank(specimen c, fig 3),192 for the punch, 48 for the blank holder and 150 for the die. The three simulations have been carried out with a punch velocity of $10 \mathrm{~mm} / \mathrm{ms}$. The blank holding force is $100 \mathrm{KN}$ and concentrated at the center of the blank holder. The contact element is of surface to surface type and the sliding and impact algorithm along interface is by the penalty method.

The use of one point quadrature makes substantial savings in computer time. The biggest disadvantage to this quadrature is the need to control the zero energy modes which arise, called hourglassing modes. A consistent hourglass control is used to prevent formation of these modes.

Two types of material models are used, the first one is the Rigid material model, where the tools (punch, die, blank holder) are approximated as rigid bodies. This had proved that it gives proper and accurate results in sheet metal forming. The second one is the Power law isotropic plasticity model. It is used to model the sheet metal. Elasto-plastic behavior with isotropic hardening is provided by this model

$\boldsymbol{\sigma}_{\mathrm{y}}=\mathrm{K} \boldsymbol{\varepsilon}^{\mathrm{n}}=\mathrm{K}\left(\boldsymbol{\varepsilon}_{\mathrm{yp}}+\overrightarrow{\boldsymbol{\varepsilon}}^{\mathrm{p}}\right)$

Where

$\boldsymbol{\sigma}_{\mathrm{y}}$ is the yield stress

$\mathrm{K}$ is the strength coefficient

$\boldsymbol{\varepsilon}_{\mathrm{yp}}$ is the elastic strain to yield 
$\boldsymbol{\varepsilon}^{\bar{P}} \quad$ is the effective plastic strain (logarithmic)

$\mathrm{n} \quad$ is the strain hardening exponent

$\boldsymbol{\varepsilon}_{\mathrm{yp}}$ is found by solving for the intersection of the linearly elastic loading equation,

$\boldsymbol{\sigma}=\mathrm{E} \boldsymbol{\varepsilon}$, with the strain hardening equation, $\boldsymbol{\sigma}=\mathrm{K} \boldsymbol{\varepsilon}^{\mathrm{n}}$, Which gives:

$\boldsymbol{\varepsilon}_{\mathrm{yp}}=(\mathrm{E} / \mathrm{K})[1 / \mathrm{n}-1]$

Table (1) shows the mechanical properties of the tested metals and the parameters characterizing the uniaxial stress elasto_plastic strain response of the metals used in the FE calculations .

Table ( 1 ) Properties of the tested metals

\begin{tabular}{|l|l|l|c|c|l|c|}
\hline material & $\begin{array}{l}\text { thickness } \mathrm{t} \\
\mathrm{mm}\end{array}$ & $\begin{array}{l}\text { Density } \\
\rho \\
\mathrm{Kg} / \mathrm{mm} 3\end{array}$ & $\begin{array}{c}\text { Modulus of } \\
\text { elasticity } \\
\mathrm{E} \text { GPa }\end{array}$ & $\begin{array}{c}\text { Poisson ratio } \\
v\end{array}$ & $\begin{array}{l}\text { Strength } \\
\text { coefficient } \\
\mathrm{K} \mathrm{GPa}\end{array}$ & $\begin{array}{l}\text { Strain hardening } \\
\text { exponent } \mathrm{n}\end{array}$ \\
\hline Mild Steel & 1 & $7.83 * 10^{-6}$ & 128 & 0.3 & 0.924 & 0.26 \\
\hline Aluminum & 1 & $2.7 * 10^{-6}$ & 38 & 0.33 & 0.2725 & 0.21 \\
\hline Brass & 1 & $8.6^{*} 10^{-6}$ & 110 & 0.35 & 0.8805 & 0.3215 \\
\hline
\end{tabular}

\section{RESULTS AND DISCUSSION}

The finite element simulations revealed that each side of the FLC has its own privacy. According to this fact each side has been dealt with separately.

\section{The right hand side (positive minor strain) of the FLD for mild steel}

The first step is to determine the level of the FLC or the major strain at localized necking in plain strain $\boldsymbol{\varepsilon}_{\mathbf{1 0}}$. According to the previous work of the authors[10], the high friction changes the strain path towards the plain strain state, the simulation is done with a high value of the coefficient of friction between the punch and the sheet $(\mu=0.35)$. The values of the strain hardening exponent $\mathbf{n}$ and the major strain at plain strain state $\boldsymbol{\varepsilon}_{\mathbf{1 0}}$ are recorded when varying $\mathbf{n}$ and keeping the initial thickness $\mathbf{t}_{\mathbf{0}}$ constant, then the values of $\mathbf{t}_{\mathbf{0}}$ and $\boldsymbol{\varepsilon}_{\mathbf{1 0}}$ are recorded when varying $\mathbf{t}_{\mathbf{0}}$ and keeping $\mathbf{n}$ constant. 


\section{The effect of strain hardening exponent $n$}

Fig (3) shows the relation between $\mathbf{n}$ and the major strain at plain strain $\boldsymbol{\varepsilon}_{\mathbf{1 0}}$ (or the level of the FLC). It is clear that the level of the FLC increases by increasing the value of $\mathbf{n}$.

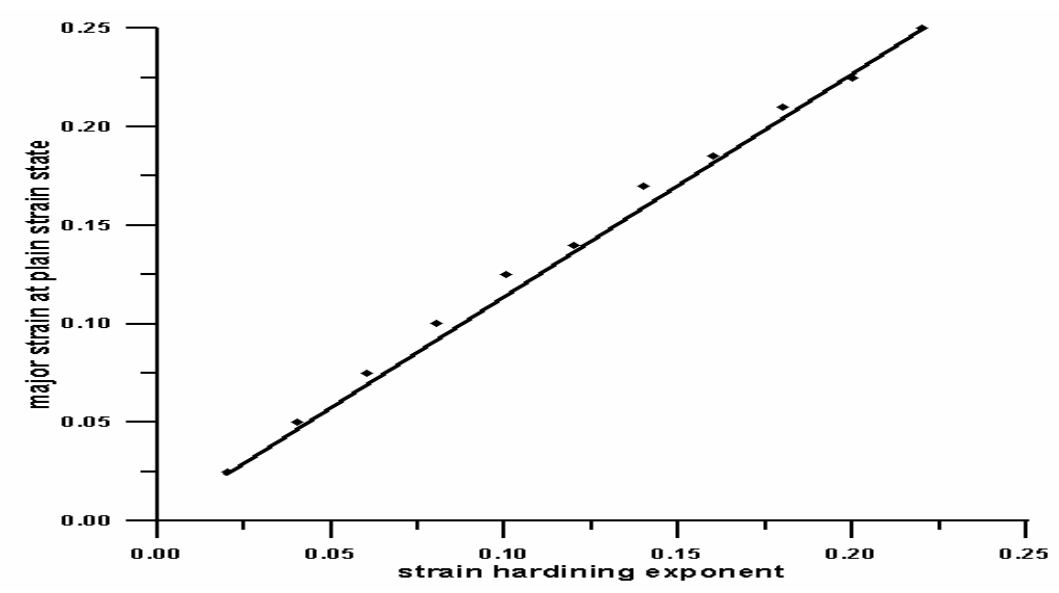

Fig (3).The relation between $\mathbf{n}$ and $\boldsymbol{\varepsilon}_{1}$

\section{The effect of initial thickness $t_{0}$}

Fig (4) shows the relation between the value of $\mathbf{t}_{\mathbf{0}}$ and the value of major strain $\boldsymbol{\varepsilon}_{\mathbf{1}}$ at plain $\operatorname{strain}\left(\boldsymbol{\varepsilon}_{\mathbf{2}}=0\right)$.Increasing $\mathbf{t}_{\mathbf{0}}$ increases $\boldsymbol{\varepsilon}_{\mathbf{1 0}}$ and hence the level of the FLC.

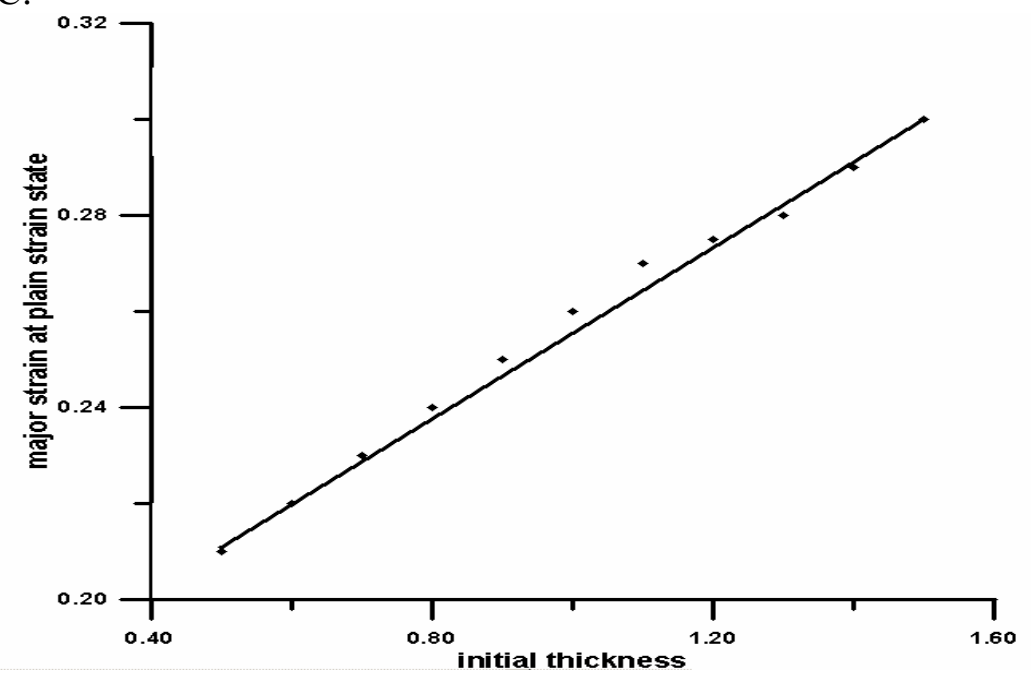

Fig(4). The relation between $\mathbf{t}_{\mathbf{0}}$ and $\boldsymbol{\varepsilon}_{\mathbf{1}}$ at plain strain 


\section{The level of FLC at plane strain state}

From fig(3) and fig(4) the combined effect of $\mathbf{n}$ and $\mathbf{t}_{\mathrm{o}}$ on $\boldsymbol{\varepsilon}_{\mathbf{1 0}}$ can be represented by the following equation

$$
\boldsymbol{\varepsilon}_{\mathbf{1 0}}=-0.087+0.092 \mathrm{t}_{\mathbf{0}}+0.9749 \mathrm{n}
$$

Where $\varepsilon_{10}$ is the major strain at localized necking in plane strain state.

From this equation the level of the FLC of mild steel at plane strain state can be determined knowing the values of $\mathbf{t}_{\mathbf{0}}$ and $\mathbf{n}$.

\section{Representation of the relation between $\varepsilon_{1}$ and $\varepsilon_{2}$ at localized necking}

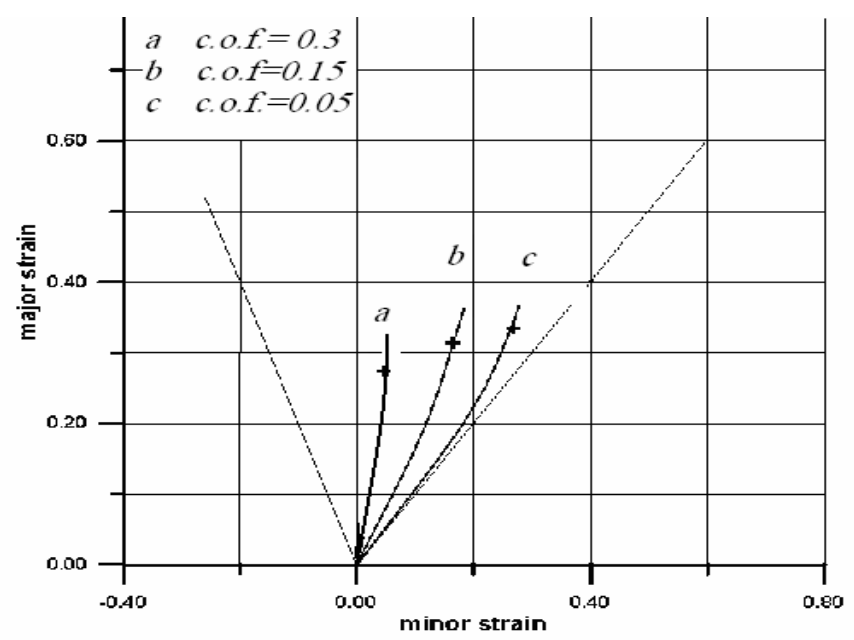

Fig ( 5 ) the effect of the coefficient of friction on strain path

Fig(5) shows different strain paths for different coefficients of friction c.o.f. and the points at which localized necking had occurred at each strain path. The curve which passes through all the points of localized necking for all the strain paths (at each value of $\mu$ ) can be represented by the following equation

$$
\boldsymbol{\varepsilon}_{1}=2.5714 \boldsymbol{\varepsilon}_{2}-0.3657 \boldsymbol{\varepsilon}_{2}^{2}+\boldsymbol{\varepsilon}_{10}
$$

Where $\boldsymbol{\varepsilon}_{10}$ can be determined from eq. (1)

Equation (2) will give a value of $\boldsymbol{\varepsilon}_{\mathbf{1}}$, at localized necking, for each corresponding value of $\boldsymbol{\varepsilon}_{2}$. 


\section{Construction of the right hand side of the FLC for mild steel}

Choosing suitable values of $\boldsymbol{\varepsilon}_{2}$ and substituting into equation (2) will give the corresponding values of $\boldsymbol{\varepsilon}_{1}$. Let these values of $\boldsymbol{\varepsilon}_{\mathbf{2}}$ and $\boldsymbol{\varepsilon}_{\mathbf{1}}$ be the horizontal and the vertical coordinates of points on the FLD. The curve which passes through all these points is the right hand side of the FLC (from the plain strain to the equibiaxial strain state).

\section{Construction of the right hand side of the FLC for}

The whole procedure is repeated for aluminum this time. The same equation (1) will be used to determine $\boldsymbol{\varepsilon}_{10}$.

For Al equation (2) becomes:

$$
\boldsymbol{\varepsilon}_{1}=-1.5902 \boldsymbol{\varepsilon}_{\mathbf{2}}+0.6559 \boldsymbol{\varepsilon}_{\mathbf{2}}^{2}+\boldsymbol{\varepsilon}_{\mathbf{1 0}}
$$

\section{Construction of the right hand side of the FLC for brass}

The same procedure is repeated as that for mild steel and aluminum. Equation (1) will be used to determine $\boldsymbol{\varepsilon}_{10}$.

For Brass equation (2) becomes:

$$
\boldsymbol{\varepsilon}_{1}=-0.3241 \boldsymbol{\varepsilon}_{2}+0.26 \boldsymbol{\varepsilon}_{2}^{2}+\boldsymbol{\varepsilon}_{10}
$$

\section{The left hand side of the FLC}

Simulation of stretching in order to draw the left hand side proved that one specimen will not cover the whole range of strain paths. At first simulation is performed using the specimen(c) shown in fig.(3), which is of smallest width among the specimens recommended by Keeler (4). At high $\mu, \boldsymbol{\varepsilon}_{2}$ is constrained [12] while $\boldsymbol{\varepsilon}_{1}$ increases on the expense of the thickness. The critical thickness $t_{\mathbf{f}}$ is reached early and necking takes place at law values of both $\boldsymbol{\varepsilon}_{\mathbf{1}}$ and $\boldsymbol{\varepsilon}_{\mathbf{2}}\left(\boldsymbol{\varepsilon}_{\mathbf{2}}=-0.08\right)$.

As $\mu$ is decreased $\boldsymbol{\varepsilon}_{\mathbf{2}}$ becomes less constrained. $\boldsymbol{\varepsilon}_{\boldsymbol{1}}$ increases on the expense of both the thickness and the width which means that reaching the critical thickness $t_{f}$ will be delayed and the stretching of the sheet will increase radialy and circumferentially(-ve) to a certain extent depending on the value of $\mu$. The limit is when $\mu$ becomes very small where $\boldsymbol{\varepsilon}_{2}=-1 / 2 \boldsymbol{\varepsilon}_{1}$ or the state of uniaxial tension is reached.

Considering the other specimen (b. fig. 3) whose width is just sufficient to resist circumferential contraction[13]. With friction, $\boldsymbol{\varepsilon}_{\mathbf{2}}$ is constrained in the contacted region. The friction force is added to the radial stretching force so that the value of $\boldsymbol{\sigma}_{\mathbf{1}}$ is increased at the edge of contact to a sufficient level such that $\boldsymbol{\varepsilon}_{\mathbf{1}}$ increases on the 
expense of the thickness and the width. By further increasing the c.o.f., $\boldsymbol{\varepsilon}_{2}$ increases in the negative direction, i.e. more contraction in the width, outside the area of contact. It is noticed that the maximum attained value of $\boldsymbol{\varepsilon}_{2}$ is $(-0.08)$. The reason is that as soon as the friction between the punch and the sheet becomes completely sticking, further increase in $\mu$ will not have any additional effect.

Decreasing $\mu$ will make $\boldsymbol{\varepsilon}_{2}$ less constrained but at the same time reduce the friction force. At very law values of $\mu$ the friction force is negligible so that $\boldsymbol{\sigma}_{\mathbf{1}}$ will have its lowest value; the width is sufficient to resist contraction. A state of plain strain takes place as $\quad \boldsymbol{\varepsilon}_{2} \quad=0$ and $\quad \boldsymbol{\varepsilon}_{1}$ increases at the expense of the thickness only.

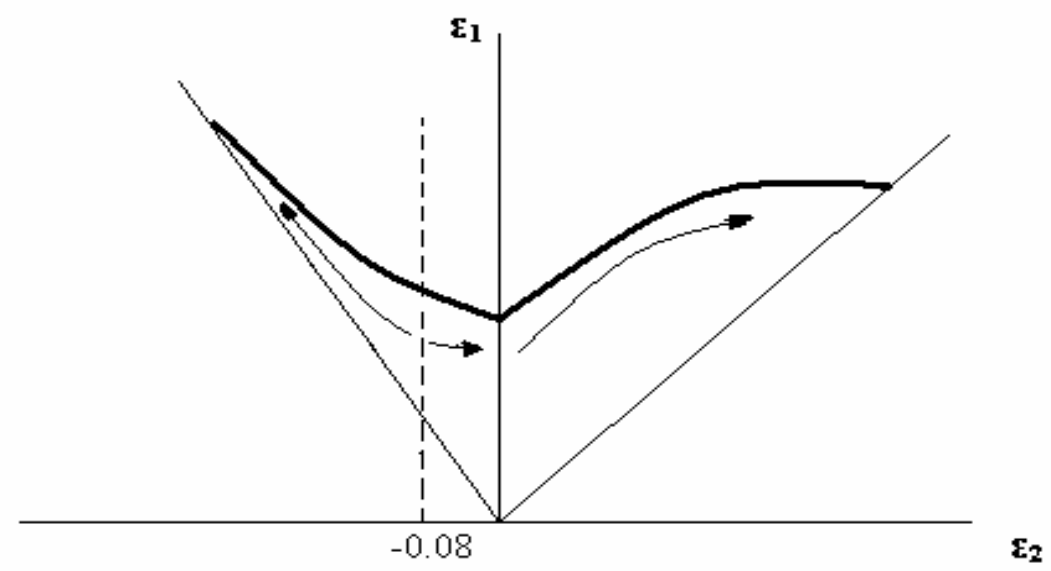

Fig.(6). As $\mu$ is decreased the strain paths change in the directions of the arrows.

From the above discussion it can be concluded that the vertical line in fig. (6) which passes through the value of $\left(\boldsymbol{\varepsilon}_{\mathbf{2}}=-0.08\right)$ separates the FLD into two regions as regards to lubrication. Specimens which show values of $\boldsymbol{\varepsilon}_{2}$ greater than (-0.08) in the negative direction, their strain paths are changed towards uniaxial stretching by lubrication. While specimens which show values of $\boldsymbol{\varepsilon}_{2}$ between (-0.08) and (0), their strain paths are changed towards plain strain state, and those which show positive $\boldsymbol{\varepsilon}_{2}$, their strain paths are changed towards equibiaxial stretching state by lubrication.

\section{The effect of strain hardening exponent $n$ and initial thickness $t_{0}$}

It is exactly the same effect which has been found on the right hand side of the FLC. So it is not necessary to determine the level of the FLC, $\boldsymbol{\varepsilon}_{\mathbf{1 0}}$, again. 


\begin{tabular}{llll} 
Al-Rafidain Engineering & Vol.14 & No.4 & 2006 \\
\hline
\end{tabular}

\section{Representation of the relation between $\varepsilon_{1}$ and $\varepsilon_{2}$ at localized necking}

It was necessary to make two simulations with two different specimens in order to cover all the strain paths. To obtain the relation between $\boldsymbol{\varepsilon}_{\mathbf{1}}$ and $\boldsymbol{\varepsilon}_{\mathbf{2}}$, the points at which localized necking had occurred at each strain path for the two specimens are considered. The equation representing this relation is found to be:

$\boldsymbol{\varepsilon}_{1}=2.5659 \boldsymbol{\varepsilon}_{2}^{2}-0.2962 \boldsymbol{\varepsilon}_{2}+\boldsymbol{\varepsilon}_{10}$

where $\boldsymbol{\varepsilon}_{\mathbf{1 0}}$ is the major strain at plain strainstatewhich can be determined from equ. (1).

\section{Construction of the left hand side of FLC for aluminum}

The whole procedure is repeated but for Aluminum this time. The same equation(1) will be used to determine $\boldsymbol{\varepsilon}_{\mathbf{1 0}}$. Equation(5) becomes:

$\boldsymbol{\varepsilon}_{1}=1.9714 \boldsymbol{\varepsilon}_{2}^{2}-0.4877 \boldsymbol{\varepsilon}_{2}+\boldsymbol{\varepsilon}_{10}$

\section{Construction of the left hand side of FLC for brass}

The same procedure is repeated as that for mild steel. Equation (1) will be used to determine $\boldsymbol{\varepsilon}_{\mathbf{1 0}}$.

Equation (5) becomes:

$$
\boldsymbol{\varepsilon}_{1}=1.3571 \boldsymbol{\varepsilon}_{2}^{2}-0.2236 \boldsymbol{\varepsilon}_{2}+\boldsymbol{\varepsilon}_{10}
$$

\section{Comparison with experimental results}

The forming limit curves, obtained by changing the strain path by means of changing the coefficient of friction., are shown in figs. (7), (8) and (9) for the Aluminum, mild steel and brass respectively. Also it is shown on the same diagrams the forming limit curves which were obtained experimentally [13].

By comparison of empirical curves with the experimental curves it is clear that the new method resulted into close FLCs to the experimental ones in the case of Al and mild steel. In the case of brass the level of the empirical FLC is lower than that obtained experimentally.According to Hill [14], the condition for localized necking is $\boldsymbol{\varepsilon}_{10}=\mathbf{n} /(1+\boldsymbol{\rho})$

where $\boldsymbol{\rho}=\boldsymbol{\varepsilon}_{2} / \boldsymbol{\varepsilon}_{1}$ is the strain ratio.

At plain strane state, $\boldsymbol{\rho}=0 \quad$ therefore $\boldsymbol{\varepsilon}_{\mathbf{1 0}}=\mathbf{n}$ 


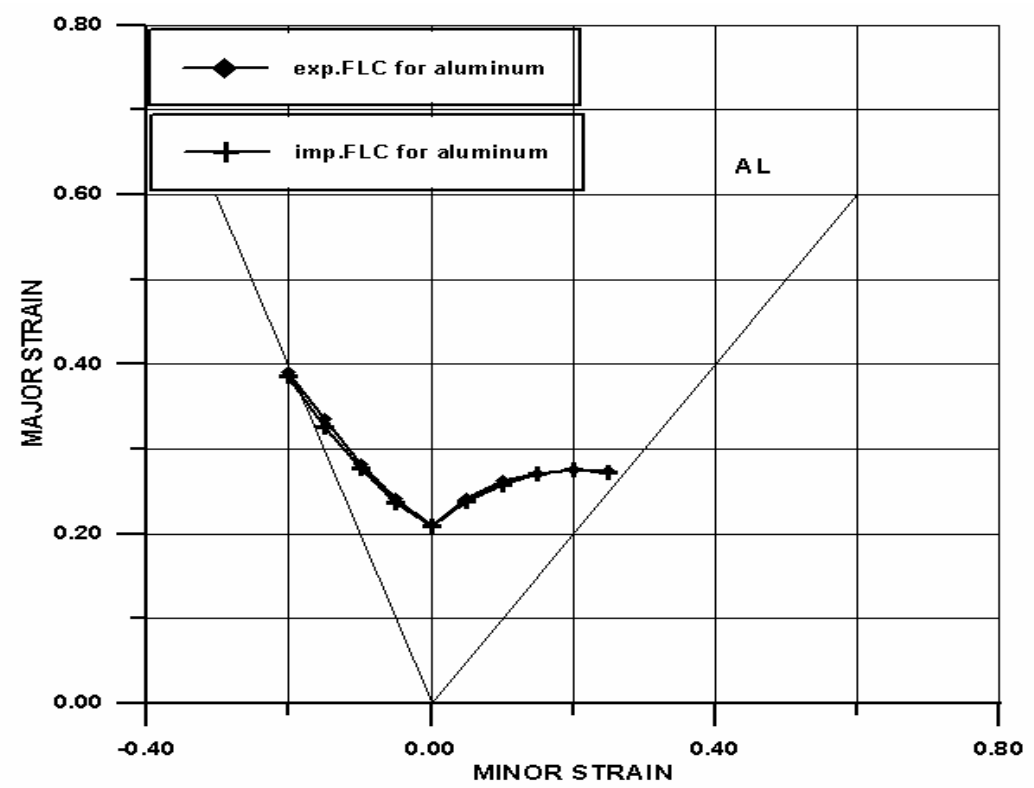

Fig (7).Comparison between empirical and experimental FLCs for $\mathrm{Al}$

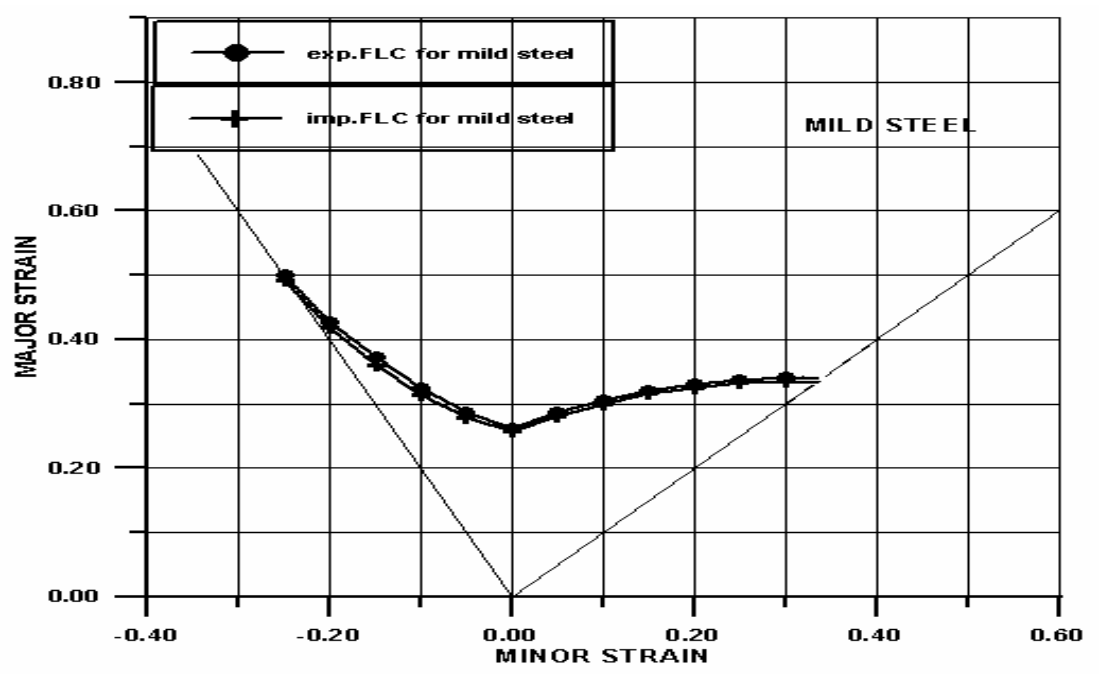

Fig. (8).Comparison between empirical and experimental FLCs for mild steel 


\section{\begin{tabular}{llll} 
Al-Rafidain Engineering & Vol.14 & No.4 & 2006 \\
\hline
\end{tabular}}

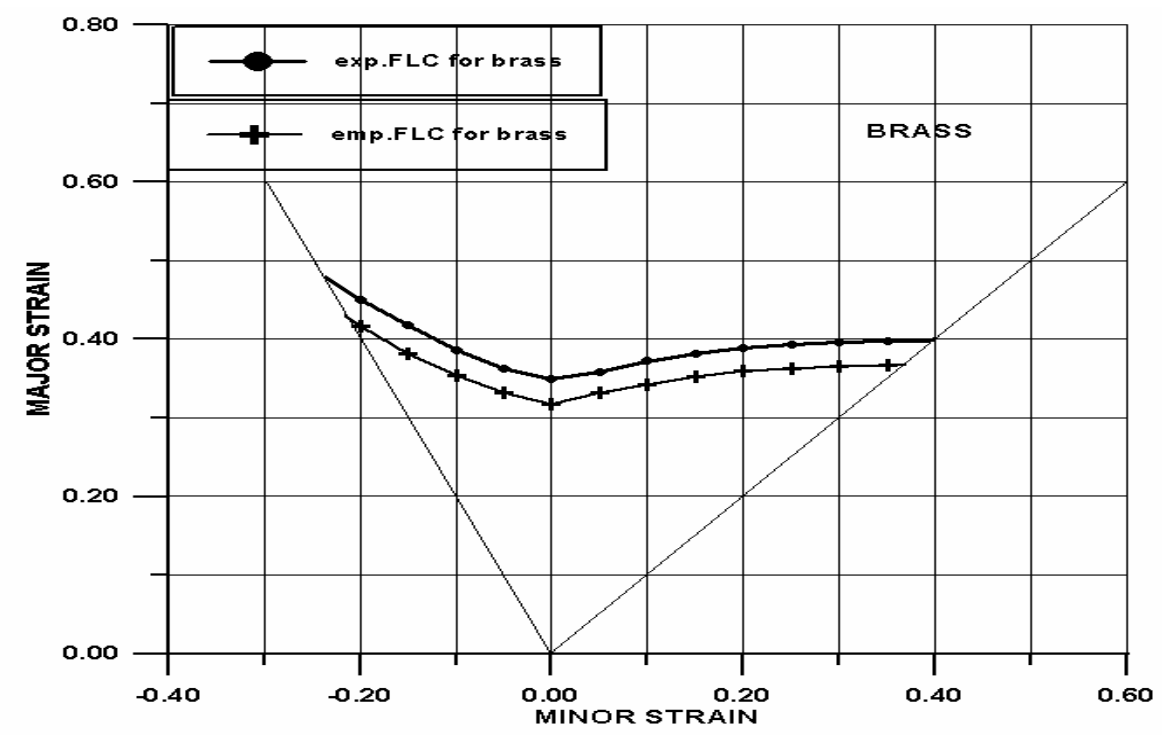

Fig (9).Comparison between the empirical and experimental FLCs for brass

By comparison of the values of $\mathbf{n}$ for aluminum, mild steel and brass which are $(0.21,0.26,0.3215)$ respectively it can be noticed that the experimental and empirical results of aluminum and mild steel and the empirical result of brass match well the results obtained by Hill theory. Only the experimental result for brass does not match. Some mistakes might have been committed in the execution or in the measurement of the experimental test for brass.

\section{CONCLUDING REMARKS}

A new method for drawing the FLC based on the fact of changing the strain path by changing the coefficient of friction. $\boldsymbol{\mu}$, between the punch and the blank, is developed. The finite element package LS-DYNA was used in the hemispherical punch test to obtain the relation between $\mathbf{n}, \mathbf{t}_{\mathbf{o}}$ and the level of the FLC at plain strain, and to obtain the relation between $\boldsymbol{\mu}$ and the strain path.

In order to draw the FLC, for each sheet metal, three formulae were deduced. The first determines the level of the FLC at plain strain. The second gives the relation between $\boldsymbol{\varepsilon}_{1}$ and $\boldsymbol{\varepsilon}_{2}$ at localized necking for the positive minor strain side of the FLC. The third gives the same relation but for the negative minor strain side.

The FLCs for three metals were drawn using this method. These curves are compared to the curves obtained experimentally. The results are very encouraging.

This new method reduces, to a large extent, the effort and time required by an 
experimental method or by a finite element simulation designed to draw the FLC.

It needs to be applied to other commonly used metals in industry to determine their relevant formulae.

\section{REFERENCES}

1. LS_DYNA version 740 . Users manual. Livermore Software Technology Corporation. Livermore ,CA 94550

2. Kim,K.J.,et al," Formability of AA5182j/polypropylene/AA5182 sandwich sheets",J.Mat.Proc.Tech.139(2003)1_7

3. Hecker,S.S.,"Simple Technique For Determining Forming Limit Curves" Sheet Metal Ind.,vol.44,1972,PP.467_469

4. Keeler,S.P. (1965),"Determination of Forming Limits In Automotive Stamping", Society Of Automotive Engineers. Technical paper No. 650535

5. Goodwin,G.M.(1968),"Application Of Strain Analysis To Sheet Metal Forming Problems In The Press Shop",Society Of Automotive Engineers,technical paper No.680093

6. Marciniak, Z. and Kuczynski, K(1967),"Limit Strains In The Process Of Stretch Forming Sheet Metal",Int.J.Mech.Soc. vol. 9, PP. 609_620

7. Hill, R.(1950),"On discontinuous Plastic States, with Special Reference To Localized necking in thin sheets", J. Mec. Phys. Soli., vol. 1,pp. 19_30

8. Storen, S. and Rice, J.R. (1975), Localized Necking In Thin Sheets,J. Mech. Phys. Solids, vol. 23, pp. 421441

9. Chow,C.L., et al," Analysis Of Sheet Metal Formability" , University Of Michigan_Dearbone, Report Brief, April 1998

10. Alsaati,A.,Ali.W.J.,Alkaissy,F.M.,"Numerical study of the effect of some forming parameters in hemispherical punch stretching".To be published in Alrafidain Engineering journal, Univ. of Mosul. Iraq.

11. ANSYS release 5.4, Ansys Inc.

12. Hosford, W.F.,Caddell R.M.,"Metal Forming Mechanics and Metallurgy", Printice Hall Int.Inc.1983, PP. 298

13. Ali, W. J. and Balod, A.O.,"Study of the factors affecting the determination of forming limit curves for sheet metal", Tikrit Engg. Sci. Journal. Vol. 12, no. 4 Univ. of Tikrit. Iraq. 2005

14. Hill, R. , "On Discontinuous Plastic States, With Special Reference to Localized Necking in Thin Sheets". Journal of the Mechanics and Physics of solids, Vol. 1, pp.19_30, 1952 